\title{
CORRIGENDUM
}

\section{A super-cusp divertor configuration for tokamaks - CORRIGENDUM}

\author{
D. D. Ryutov \\ doi:10.1017/S0022377815001026, Published by Cambridge University Press, \\ 26 August 2015
}

An error was made in figure caption 4: there should be '... (Ryutov \& Umansky 2013)' instead of '... (Kotschenrether et al. 2004)'. This regretful error occurred in the course of conversion of the original numbered list of references to an alphabetical list.

\section{REFERENCE}

Ryutov, D. D. 2015 A super-cusp divertor configuration for tokamaks. J. Plasma Phys. 81, 495810516. 